\title{
The role of openness in explaining innovation performance in a regional context
}

\author{
Anna D'Ambrosio 1 (D) Roberto Gabriele ${ }^{2}$ (D) Francesco Schiavone S $^{3,4}$ • \\ Manuel Villasalero ${ }^{5}$
}

Published online: 12 September 2016

(C) The Author(s) 2016. This article is published with open access at Springerlink.com

\begin{abstract}
We investigate the role of search strategy in shaping firms' innovation performance. Firms use a wide range of external actors and sources to help them achieve and sustain innovation. In particular, the extension (breadth) and the relevance (depth) of such sources determine firms' ability to extract and exploit knowledge and new ideas and, thus, to be innovative. Using a sample of firms in a regional context active in R\&D, we built separate measures of breadth and depth for local (on a regional scale) and global (outside the regional context) search. This allows us to investigate whether localized or global knowledge spillovers are in place. We find that a wider set of partners increases coordination costs, while greater depth in search strategies contributes to innovation. We find that a more diversified search strategy at the local level (greater breadth of search) results in significant payoffs in terms of innovation, while diversifying the partnership with Italian partners has a smaller, although still positive, effect. In contrast, the benefits of depth of innovation are greatest at the global level. In addition, a broader set of information sources for $R \& D$ projects has a significant positive effect on innovation. Finally, firms that resort to R\&D subsidies are less innovative.
\end{abstract}

Manuel Villasalero

manuel.villasalero@uclm.es

Roberto Gabriele

roberto.gabriele@unitn.it

1 Department of Economics and Statistics "Cognetti de Martiis", University of Turin, Lungo Dora Siena 100, 10153 Turin, Italy

2 Department of Economics and Management, University of Trento, Via Inama, 5, Trento, Italy

3 Department of Management Studies and Quantitative Methods, Universita degli Studi di Napoli Parthenope, Palazzo Pacanowski Via Generale Parisi, 13, 80132 Naples, Italy

4 Department of Strategy and Management, Paris School of Business, 59 Rue Nationale, 75013 Paris, France

5 Facultad de Derecho y Ciencias Sociales, Universidad de Castilla-La Mancha, Ronda de Toledo, s/n, 13071 Ciudad Real, Spain 
Keywords Openness $\cdot$ Search strategies $\cdot$ Innovation $\cdot$ Innovative performance $\cdot R \& D$ regional policy

JEL Classification O31 $\cdot \mathrm{R} 11 \cdot \mathrm{D} 83$

\section{Introduction}

To carry out their innovation processes, innovative firms often rely on sources of knowledge that are external, that is, located outside the firm's boundaries. This is due to the increasing availability and mobility of knowledge workers, the flourishing of the internet and venture capital markets and the broadening scope of possible external suppliers (Lee et al. 2010). In other words, innovative firms have shifted toward the so-called Open Innovation (OI) model (Chesbrough 2003a; Chesbrough et al. 2006).

The OI paradigm recognizes the creation of rich, inter-organisational R\&D networks comprising both private and public actors. The relationships involved in this paradigm can be interpreted as firms actively investing in searching for new external sources of knowledge. Thus, firms' innovative performance is influenced by both their internal search strategy (Villasalero 2014a) and their external search strategy (Laursen and Salter 2006; Zeng et al. 2010).

In this paper, we empirically link the breadth and depth of firms' external search strategies to their innovative performance, exploring how differences in search strategies among firms influence their ability to patent new ideas. By doing so, this study follows the model advanced by Leyden and Link (2015) in which the entrepreneurial process is seen as the interplay between social networks and desired innovations. We build on the concepts proposed by Cohen and Levinthal (1990), who argue that the ability to exploit external knowledge is a critical component of innovative performance. We begin from the classification of search dimensions introduced by Laursen and Salter (2006), who develop the concepts of breadth and depth as two components of the openness of individual firms' external search strategies. We then extend the concepts to take into account the geographical scope of search breadth and depth. In particular, we investigate whether relying only on localized knowledge or also on global knowledge sources has different implications in terms of patenting activity. In addition, recognizing that public policies play a critical role in promoting the adoption of OI among firms (Chesbrough and Vanhaverbeke 2011), we study if and how R\&D subsidy policies alter firms' search paths and, thus, their ability to innovate. Furthermore, we recognize that such search strategies may be costly.

This research is based on a survey of the innovation activities and research collaboration of Italian firms in a small and innovative region of northern Italy, the Trentino Province. This survey allows us to construct a measure of depth that takes into account both the subjective importance of partners in R\&D collaborations and the duration of the relationships. Using Poisson models, we show that the two dimensions have differing ability to spur innovation activity: rather than breadth, depth of search seems to be more important. In terms of breadth, we find that, rather than being spurred by a more diversified network of R\&D partners per se, innovation is spurred by a more diversified network of suppliers of information on funding opportunities. In addition, we find that public policy positively mitigates the depth of firms' search strategies and, thus, can be interpreted as indirectly altering the search path. 
The paper is organised as follows. Section 2 presents the research hypotheses. Section 3 discusses the study's context, the data used and the methods employed. Section 4 presents the results. Finally, Sect. 5 summarises the study's main conclusions, points out its relevant implications and identifies limitations and future perspectives.

\section{Hypotheses}

\subsection{The role of external sources of knowledge}

The OI model suggests that the advantages that firms gain from internal $R \& D$ expenditures have declined. Compared to previous decades, innovative firms now spend less on intramuros $R \& D$, and yet they are able to successfully innovate by relying on knowledge from a wide range of external sources. This erosion in the strategic advantage of internal R\&D is caused by several factors, the most important of which is the increasing inability of firms to appropriate and control their R\&D investments (Chesbrough 2003a, b).

The evolutionary perspective lends support to the OI framework, showing that a wide range of external sources of knowledge provides opportunities for firms to choose among different technological paths (Dosi 1988; Metcalfe 1994). In addition, in evolutionary theory, search strategies are strongly influenced by the richness of technological opportunities available in the environment and by the search activities of other firms (Nelson and Winter 1982; Levinthal and March 1993). The use of various knowledge sources by an individual firm is partly shaped by the external environment, including the availability of technological opportunities, the degree of turbulence in the environment and the search activities of other firms in the industry (Cohen and Levinthal 1990; Klevorick et al. 1995).

Adopting this theoretical approach, Laursen and Salter (2006) provide a test of OI strategies of firms, looking at the various search channels that firms use to upgrade their knowledge bases. They define two dimensions of the search for external sources of knowledge: (1) the breadth of search, as measured by the number of external sources or search channels that firms rely upon in their innovative activities; (2) the depth of search, as defined by the extent to which firms draw deeply from various external sources. They find that both dimensions of search have an inverted U-shaped relationship with innovative performance.

Ahuja (2000) has found that indirect and direct ties influence a firm's ability to innovate, but that the effectiveness of indirect ties is moderated by the number of the firm's direct ties. Within the same theoretical framework, Rosenkopf and Nerkar (2001) explore the role of boundary-spanning searches and find that search processes that do not span organizational boundaries have less effect on subsequent technological evolution. More closely related to our contribution on collaboration variety and effort is the investigation by Powell et al. (1996) on inter-organizational collaboration in biotechnology, which assesses the contribution of collaboration to learning and performance and shows that firms embedded in benefit-rich networks are likely to have greater innovative performance. All these studies show the relevance of firms' OI strategies to their search for innovative opportunities, and they suggest that performance differences among firms can be explained, all else being equal, by the degree of openness of the organizations. Katila (2002) and Katila and Ahuja (2002) investigate the link between search strategy and innovative performance as measured by patent activity, showing that the depth and scope of search processes can influence the potential for innovation. 
Hence, to understand firms' innovation activities, we must consider not only internal R\&D efforts, but also external sources of knowledge and firms' search activities (Villasalero 2015). Accordingly, we investigate the role of the search channels represented by various kinds of collaboration partners, including universities, public institutions and other private firms, and the scope of these collaborations-local versus global relationshipsthat firms use to search for innovative opportunities. The available evidence suggests that what is important is not only the variety of sources of knowledge but also their quality. In our framework, we can test these two factors separately, using a variable that summarizes the variety of collaboration, similar to the "breadth" indicator built by Laursen and Salter (2006), and a variable that further develops their measure of "depth" and captures the overall intensity of collaboration as a proxy for its quality. We should note that, in our framework, firms are SMEs and experience shortcomings typical of such companies. In particular, firms are financially constrained, they pay a high cost to coordinate with collaborative partners and they can potentially benefit significantly from ideas that come from outside their organisations. Hence, in contrast to Laursen and Salter, we expect firms' search strategies to have differentiated effects on innovation. On the one hand, a wider set of important and durable relationships - that is, greater depth - is expected to contribute to a smooth, dense flow of knowledge and, thus, to facilitate innovation. On the other hand, a more differentiated set of partners - that is, greater breadth - could either contribute to extending the knowledge stock with new sources of knowledge or increase the costs of maintaining a differentiated network of relationships. We expect the latter effect to prevail in SMEs.

Given the above discussion, our first hypotheses are the following.

Hypothesis 1a Greater breadth in search strategies-a more differentiated set of partners-harms innovation performance of firms due to the increased coordination costs it imposes.

Hypothesis 1b Greater depth in search strategies - a higher degree of exploitation of knowledge sources-benefits firms' innovation performance.

\subsection{The role of the geographic scope of search}

The pertinent literature debates localized knowledge spillovers (Breschi and Lissoni 2001)—which are likely to play a particularly relevant role in a regional context like the one under scrutiny-in which the majority of firms are SMEs (Basile et al. 2012; Acs et al. 2013; Schiavone 2008a, b). SMEs that are active in a regional context may benefit differently from localized knowledge spillovers than from flows of knowledge originating from more geographically distant sources (Villasalero 2013). The reasons leading to collaboration, the selectivity in the partnerships and the tacitness of the knowledge exchanged are likely to differ in localized versus global partnerships. In addition, Granovetter (1985) and Burt (1992) suggest that innovation is more likely to arise in encounters between nonredundant sources of information (at 'structural holes' or by 'weak' rather than 'strong ties'). To address these issues, we measure the breadth and depth of search strategy at various geographical levels. We build the measures of breadth of search by counting the number of different institutional partners at the regional, Italian and international levels, and we measure depth - that is, the intensity of relationships as measured by the intensity of collaboration - at the regional, Italian and international levels. The distinction between breadth and depth of search seems particularly useful in this context. Regarding depth, we 
can expect a geographical gradient to emerge. Indeed, the argument about the redundancy of 'strong' ties is likely to be more applicable to deeper ties with knowledge sources located in closer geographical proximity. In contrast, deep ties with a broader geographic scope can be considered to have a greater 'boundary-breaking' potential and, thus, to be more useful to innovation. Regarding breadth, it is a priori ambiguous whether geography affects the effect of partner variety on innovation. On the one hand, a more differentiated local network may contribute to innovation by offering fine-tuned solutions that capitalize on local specificities, but it may lead to lock-in effects and dependency on that local system. On the other hand, a diversified network of foreign partners may contribute to opening up the local system to external sources of knowledge, but it can also be expected to entail non-negligible coordination costs. Considering that most firms in our data are SMEs, we expect the benefits of local collaboration and the costs of international collaboration to prevail.

To guide the empirical analysis, we propose the following hypotheses.

Hypothesis 2a Greater breadth at the local level leads to more innovation, while a more diversified network of partners at the international level has a smaller or even a negative effect on firms' innovative performance.

Hypothesis 2b Greater depth of search with international partners has a positive relationship on firms' innovation performance, while local depth of search has a negative effect on innovation.

\subsection{Role of financing sources}

R\&D activity involves important start-up costs that must be paid upfront-before firms obtain any returns from these activities in the form of improved innovation performanceand that are, to a large extent, sunk (Máñez et al. 2014). In addition, there are fixed costs to carrying on this activity (Aw et al. 2011). Firms must cover these costs by using their own funds and/or by borrowing. There is a negative relationship between credit constraints and R\&D, based on the existence of information asymmetries (Leland and Pyle 1977), high adjustments and sunk costs (Arrow 1962) and lack of collateral (Hall 2002; Hall and Lerner 2010; Máñez et al. 2014).

As a result, $R \& D$ investments are typically financed through internal sources, especially in the case of SMEs, and the use of external sources can be extremely difficult and expensive for firms (David et al. 2000). Under such conditions, the main problem of SMEs is to find external sources of money. A more diversified set of information sources about potential financing opportunities is likely to enlarge the ability of the firm to secure external funding and, hence, to free up resources for innovation. In addition, in our context, using external sources of money can lead to spillovers that can alter firms' innovative performance (Takalo et al. 2013).

Hypothesis 3 Firms relying on a broader set of sources are expected to have comparatively less binding budget constraints and to more effectively allocate resources to the right technological partners, allowing them to achieve better innovative performances as measured by the number of patents issued.

To deepen the analysis of the role of financing capabilities, we also investigate the role of public subsidies as measured by firms' abilities to get public grants for R\&D investments. This aspect is particularly important in the context under investigation. Indeed, 
Trentino was one of the Italian provinces in which R\&D policy was extremely important during the period under scrutiny (Corsino et al. 2015). A number of studies have found positive effects of firms' increased R\&D effort, although significant doubt persists about the ability of R\&D effort to spur firm performance (Cerulli 2010; Garcia-Quevedo 2004). On the one hand, R\&D subsidies can alleviate firms' budget constraints and contribute to innovation; on the other hand, the application process for public funding is costly, and firms under time and budget constraints may choose to focus on their own investment efforts in R\&D rather than fundraising efforts. To a large extent, the net effect is an empirical issue. As a result, we propose two competing hypotheses.

Hypothesis 4a Firms that resort to R\&D subsidies are less competitive at a global scale: That is, innovative performance is negatively affected by the use of public money once other factors are controlled for.

Hypothesis 4b Firms that resort to R\&D subsidies are more competitive at a global scale: That is, innovative performance is positively affected by the use of public money once other factors are controlled for.

Another interesting aspect to investigate is the role of breadth and depth of search strategy in shaping the effect of public subsidies on innovation performance. In particular, we are interested in understanding if and how public subsidies can mitigate or amplify the effects of the two dimensions of search. For example, the application for a grant could change the selection criteria for R\&D partners. In particular, selection for a grant could result in choosing collaboration partners preferred by the grantor instead of those with higher R\&D potential. This could harm firms' innovation performance. At the same time, public funds could help firms by deepening their collaboration with R\&D partners by contributing more money to the project, thereby stimulating the joint research effort and resulting in a greater innovation outcome. We expect that the moderating effect of subsidies on firms with deeper ties will be positive, as those firms will be able to capitalize on these ties when using public funding. Again, the effect of breadth is, instead, ambiguous a priori. However, if breadth is increased in response to application requirements, rather than as a consequence of pre-existing depth, it is likely to become a cost rather than an asset for firms. Hence, we propose the following hypotheses.

Hypothesis 5a R\&D subsidies negatively mitigate the effect of breadth of search.

Hypothesis 5b R\&D subsidies amplify the effect of depth of search.

\section{The context of the study and the data}

\subsection{The local context}

The context of the study is the Trentino Province of Italy, located in the country's northeast, which began to grow in the 1980s, mainly due to developments in the manufacturing and tourism sectors. Currently, the province has a well-developed production system and is characterized by the wide prevalence of SMEs. It is located in one of the most-developed regions (at NUTS 2 level) in Europe. During the time period under scrutiny in the present study, 2010-2012, the average per-capita GDP amounted to ca. 28k euros (Eurostat 2015). Since 1999, the R\&D activity of local firms has been fostered by Provincial Law 6/99 (PL 6/99), which can be considered a typical case of regional policy 
designed to further the specific objectives of the region and targeting local firms (Gabriele 2013). Specifically, firms' R\&D efforts are aided through direct subsidies co-financing their research projects (Corsino et al. 2015). Participation in the subsidy scheme is based on voluntary application. The projects are selected by a scientific committee that carefully evaluates all aspects of the projects, including their intended network of collaborations. Interestingly, the companies active in Trentino Province can access public money only through the local authorities. Given its characteristics, such a framework seems to be a well-suited subject for our investigation in terms of structure of the economic system, presence of big research institutions with strong ties to the production system, presence of place-based R\&D policies and ability to collect specific information about the economic and $R \& D$ activities of firms.

\subsection{The sample}

The data used in this paper come from a unique dataset derived by integrating three data sources: (1) a dedicated survey on R\&D collaborations administered by the Statistical Office of the Province of Trento (ISPAT); (2) an annual Istituto Nazionale di Statistica (ISTAT) survey on firm R\&D activities (RS1) and (3) the local authorities' database on R\&D subsidies received by local firms for the promotion of economic activities: Agenzia Per l'Incentivazione delle Attività Economiche (APIAE).

The dedicated survey on firm collaborations in Trentino Province (SpillSu) was conducted from September 2014 to February 2015. The main objective of this survey was to collect information about the collaboration networks and knowledge spillovers of R\&D firms in the province. The survey questionnaire addressed the years from 2010 to 2012 and was administered via web. It was composed of three main parts covering the following.

- Number and characteristics of each firm's partners (each firm could indicate a maximum of five partners): denomination of the partner, location, rank of the partner, duration of the relationship, perceived quality and costs of the relationship, reasons for choosing and maintaining the relationship with each partner.

- Main research projects carried out by the interviewees (each firm could indicate a maximum of five projects): denomination of the project, keywords, costs, main objectives and any subsidies received by the local authorities.

- Number and location of main competitors.

The list of firms surveyed, together with those from the ISTAT RS1 survey, represents all those firms with legal residence and with a production plant in Trentino Province that undertook some kind of R\&D activity, in-house and/or outsourced, during the period under analysis. Hence, the final sample is representative of the firms active in R\&D in Trentino Province. Specifically, we included in the list of potential interviewees all firms whose responses to the RS1 survey indicated that they had carried out R\&D activities (either internally or outsourced) during at least 1 year between 2010 and 2012. We also included all non-surveyed beneficiaries of $\mathrm{R} \& \mathrm{D}$ subsidies that were provided by APIAE under the framework of PL6/99 during the same period. The selected sample comprised 213 firms; of these, 164 responded, which was a $77 \%$ response rate. ${ }^{1}$

\footnotetext{
${ }^{1}$ It is noteworthy that some firms declined to respond to the survey because they considered their network of collaborators to be key competitive information that they did not want to disclose. Recognizing this, the survey asked for the denominations of the partners without requiring further specifications. Later, those denominations were matched to fiscal codes and then to administrative data. This process benefited greatly
} 


\subsection{Measures}

Table 7 shows results of our baseline specification, which are based on models similar to those used by Laursen and Salter (2006), with some variations aimed at deepening the analysis. Below, we present and discuss all the variables used in the study, which are divided into three groups: dependent variable, independent variables and controls.

\subsubsection{Dependent variable}

Our outcome variable of interest is the innovation performance of firms, as measured by the number of patent applications filed by a subset of firms in Trentino Province declaring that they regularly carry out R\&D activities (Villasalero 2014b). This implies an important change with respect to the model in Laursen and Salter, in which the dependent variable is the share of the firm's turnover derived from innovative products, and the estimation is performed through a Tobit model. Due to the count nature of our dependent variable, we apply a Poisson model, which is nonlinear; hence, we do not include quadratic terms in our regression, as their interpretation in terms of marginal effects would be only partially informative. Similarly, the interaction terms can be interpreted only with great caution, as in other non-linear models (Ai and Norton 2003; Norton et al. 2004).

\subsubsection{Independent variables}

Our explanatory variables represent the breadth and the depth of firms' openness to external search. In Model (1) in Table 6), the breadth and depth variables are constructed as in Laursen and Salter (2006). Thus, the variable Breadth represents a proxy of the scope of the search and is the number of types of partners indicated by the firm. Possible types of partners are research institutions, other institutions and firms. Similarly, the variable Depth_Inten sums up the number of partners that the respondent has ranked as being among the most important.

Departing from Laursen and Salter, we exploit the greater richness of our ad hoc survey data to derive another measure of depth, one that is in line with the definition provided in Laursen and Salter: 'the extent to which firms draw intensively from different search channels or sources of innovative ideas' (2006: 140). The Spillover survey asked the respondents to indicate up to five partners with whom they collaborated on R\&D activities. The responses were ranked according to a series of variables, including the importance of the partner and the duration of the relationship. We expect that the extent to which a firm draws intensively from a given channel may depend on the importance of the tie, its duration, or both. Hence, for each partners indicated by the respondent, we multiplied the rank and the duration and summed up all results. The firms could indicate up to five partners, but many chose to indicate fewer; therefore, we assume that all the partners mentioned are comparatively important to the respondent. The resulting measure, Depth, is used in Model (2) in Table 6 and Models (1) and (2) in Table 7.

In Model (3) in Table 6 and Models (3) and (4) in Table 7, we split the breadth and depth variables by geography. Breadth_TN corresponds to the count of the institutional partners of each interviewed firm that are headquartered in Trentino Province; Breadth_IT

Footnote 1 continued

from assistance by those in the Statistical Office of the Province of Trento (ISPAT), whose thorough knowledge of the local actors significantly smoothed the matching process. 
counts the institutional partners located outside Trentino Province but within Italy; and Breadth_EX counts the institutional partners located outside Italy. Depth_TN is our measure of Depth restricted to the partners located in Trentino Province; Depth_IT is our measure of Depth calculated for the partners located outside Trentino Province but within Italy; and Depth_EX is the same measure calculated exclusively for foreign partners.

As in Laursen and Salter, we also include the total number of collaborations declared by the respondent. Indeed, while the survey requested detailed information about five selected partners, one of the first questions asked the respondents to indicate the total number of partners with which they collaborate. This information was encoded in the variable Coll_Inten. The advantage of such a measure is that it actually measures the effort in coordinating the knowledge flows derived from various sources.

In the literature, the financial constraints to which the firm is subject are measured by cash flow (Fazzari et al. 1988). This choice has several shortcomings and has been criticized for its inability to properly identify external financial constraints (Kaplan and Zingales 1997). Consequently, unlike in existing literature, our investigation of the role played by financial constraints on innovation performance relies on direct information about the number of sources from which the firm received information on ways to finance its $R \& D$ activity (Breadth_Fin). Likewise, for similar reasons, we use the inverse of a firm's access to public R\&D subsidies as a proxy of financial constraints. Hence, we exploit information about the granting of public R\&D subsidies to firms as measured by the total number of grants given to a particular firm during the period under investigation (PubSub).

\subsubsection{Control variables}

We also include a set of controls similar to those included in Laursen and Salter. First, we include a measure of $\mathrm{R} \& \mathrm{D}$ intensity, RDint, constructed as the ratio between $\mathrm{R} \& \mathrm{D}$ expenditures and the full-time equivalent labour input for $R \& D$ activities. This measure simultaneously captures the size and relative effort of the firm in carrying out $R \& D$ activities. It has the advantage of being free of the important collinearity between the firm's R\&D expenditures and the number of employees devoted to R\&D activities. Indeed, a major share of the R\&D costs in our sample are staff costs. Then, we include a dummy variable, Geomarket, which is equal to 1 if the firm has competitors in foreign countries and is equal to 0 otherwise. This measure is meant to capture the external orientation of firm sales. We also include a binary variable, Dummy_hightech, which is equal to 1 if the firm belongs to the Statistical classification of economic activities in the European Community (NACE) that are divisions classified as high-tech manufacturing or knowledgeintensive services ${ }^{2}$ and is equal to 0 otherwise.

\section{Results}

\subsection{Descriptive analysis}

The survey sample comprises firms that carried out R\&D activities for at least 1 year during the 2010-2012 period; some of these firms also benefited from public incentives for R\&D (see Table 1).

\footnotetext{
${ }^{2}$ http://ec.europa.eu/eurostat/cache/metadata/Annexes/htec_esms_an3.pdf.
} 
Table 1 Summary statistics of the main variables used in the analysis

Our elaborations on data SpillSu

\begin{tabular}{lcrrll}
\hline Variable & $\mathrm{N}$ & \multicolumn{1}{c}{ Mean } & \multicolumn{1}{c}{ SD } & Min & Max \\
\hline PatDummy & 84 & 17.857 & 0.385 & 0 & 1 \\
PatCount & 84 & 0.726 & 2.505 & 0 & 18 \\
Breadth & 84 & 1.250 & 0.917 & 0 & 3 \\
Breadth_TN & 84 & 0.548 & 0.813 & 0 & 3 \\
Breadth_IT & 84 & 0.167 & 0.511 & 0 & 3 \\
Breadth_EX & 84 & 0.012 & 0.109 & 0 & 1 \\
Depth_Inten & 84 & 1.309 & 1.006 & 0 & 3 \\
Depth & 84 & 23.333 & 20.033 & 0 & 60 \\
Depth_TN & 84 & 10.905 & 13.567 & 0 & 56 \\
Depth_IT & 84 & 9.024 & 11.802 & 0 & 44 \\
Depth_EX & 84 & 3.381 & 8.362 & 0 & 36 \\
RDint & 84 & 62.953 & 41.808 & 7 & 253.462 \\
Geomarket & 84 & 0.369 & 0.485 & 0 & 1 \\
Dummy_hightech & 84 & 0.0714 & 0.259 & 0 & 1 \\
PubSub & 84 & 0.798 & .979 & 0 & 3 \\
PubSub_Dummy & 84 & 0.476 & 0.502 & 0 & 1 \\
Coll_Inten & 84 & 4.119 & 6.652 & 0 & 37 \\
Breadth_Fin & 84 & 1.702 & 1.874 & 0 & 7 \\
\hline
\end{tabular}

On average, the firms interviewed spent $1,670,374 €$ per year on $R \& D$ activities, albeit with substantial variation across firms (the coefficient of variation is 6.27), and they employed, on average, 25 researchers in R\&D activities, corresponding to 18.8 full-time equivalents (FTEs). This led to an average measure of R\&D intensity, RDint, calculated as the ratio between $R \& D$ expenditure and $R \& D$ employment, of 62.953 . In $53.5 \%$ of the cases, the $R \& D$ expenditures derive totally or partially from outsourcing $R \& D$ activities to third parties, which are other private firms. In addition, $17.9 \%$ of the firms stated that their $\mathrm{R} \& \mathrm{D}$ activities led to filing patent applications. Of these firms, the median number of applications filed during the year was two. Table 1 also shows that nearly half of the firms, $47.6 \%$, benefited from public subsidies of R\&D activities in the timeframe under consideration; about $25 \%$ of the beneficiaries received more than one subsidy during this period.

Regarding inter-firm relationships, $25 \%$ of the firms stated that they did not cooperate with any partners, while nearly $75 \%$ reported cooperative ties with one or more firms. While the number of partners indicated ranged from 0 to 37, the median firm had 2 partners. Of those firms that had no cooperative ties, about a half, $55.6 \%$, had no ongoing research projects either. The remaining firms had ongoing research projects but no cooperative ties (see Table 2).

Regarding partner location, $56.9 \%$ of the firms had at least one partner located outside Trentino Province, while $20.7 \%$ indicated foreign partners (Table 3). In addition, $56.95 \%$ of the firms counted at least one research centre or university among their partners; $59.62 \%$ indicated at least one firm and $9.52 \%$ indicated that local authorities were among their partners (Table 4). 
Table 2 Number of firm collaborations and R\&D projects

Our elaborations on data SpillSu

\begin{tabular}{llll}
\hline No. of ties & No. of firms & No. of projects & Firms \\
\hline 0 & 21 & 0 & 18 \\
1 & 14 & 1 & 29 \\
2 & 8 & 2 & 12 \\
3 & 13 & 3 & 11 \\
4 & 4 & 4 & 6 \\
5 & 10 & 5 & 4 \\
More than 5 & 14 & More than 5 & 3 \\
Total & 84 & Total & 84 \\
\hline
\end{tabular}

Table 3 Partners outside the region

\begin{tabular}{llllll}
\hline Variable & Obs. & Mean & SD & Min & Max \\
\hline Presence of partners in other Italian regions & 116 & 0.569 & 0.497 & 0 & 1 \\
Presence of partners located abroad & 116 & 0.207 & 0.407 & 0 & 1 \\
No. of partners in other Italian regions & 116 & 1.103 & 1.226 & 0 & 5 \\
No. of partners abroad & 116 & 0.345 & 0.781 & 0 & 4 \\
\hline
\end{tabular}

Our elaborations on data SpillSu

Table 4 Frequency of partner types

\begin{tabular}{lllllll}
\hline \# of partners & Research institutions and universities & $\%$ & Other institutions & $\%$ & Firms & $\%$ \\
\hline 0 & 37 & 44.05 & 76 & 90.48 & 34 & 40.48 \\
1 & 26 & 30.95 & 7 & 8.33 & 22 & 26.19 \\
2 & 14 & 16.67 & 1 & 1.19 & 5 & 5.95 \\
3 & 3 & 3.57 & - & - & 11 & 13.10 \\
4 & 4 & 4.76 & - & - & 8 & 9.52 \\
5 & - & - & - & - & 4 & 4.76 \\
Total & 84 & 100 & 84 & 100 & 84 & 100 \\
\hline
\end{tabular}

On average, firms reported a positive assessment of the quality of their ties with respect to their $\operatorname{costs}^{3}$ (Table 5). However, the costs of partnerships are not considered negligible. Indeed, if the quality of the relationship was rated 'High' or 'Extremely high', the level of cost was rated 'Quite high' or 'Not so high'.

\footnotetext{
3 To avoid framing and anchoring effects among the respondents, all subjective assessments in the survey asked the interviewees to indicate their evaluations on a Likert scale ranging from 1 (Very important/Very high) to 6 (Not relevant/Low). In this section, the answers have been recoded to increase clarity. Hence, in all following tables, 1 corresponds to the minimal evaluation (Not relevant/Low) and 6 corresponds to the maximal evaluation (Very important/high).
} 
Table 5 Interviewees' assessments about the quality, costs and motivations of their R\&D partnerships

\begin{tabular}{|c|c|c|c|c|}
\hline & \multicolumn{2}{|l|}{ All partners } & \multicolumn{2}{|c|}{$\begin{array}{l}\text { Most important partners } \\
\text { (subj. evaluation) }\end{array}$} \\
\hline & Average value & SD & Average value & $\mathrm{SD}$ \\
\hline Quality of the partnership & 5.23 & 0.89 & 5.42 & 0.83 \\
\hline Cost of the partnership & 3.63 & 1.23 & 3.67 & 2.04 \\
\hline \multicolumn{5}{|l|}{ Motivations for the partnership } \\
\hline Capitalizing on partners' experiences & 4.51 & 1.47 & 4.57 & 1.53 \\
\hline Integration of competences in applied research & 4.36 & 1.59 & 4.65 & 1.44 \\
\hline Exchange of experiences & 4.25 & 1.77 & 4.34 & 1.77 \\
\hline Integration of competences in product development & 4.25 & 1.60 & 4.32 & 1.61 \\
\hline Exploiting market opportunities & 3.92 & 1.73 & 4.01 & 1.76 \\
\hline Integration of competences in base research & 3.38 & 2.00 & 3.75 & 1.22 \\
\hline
\end{tabular}

Our elaborations on data SpillSu

\subsection{Econometric analysis}

Given the nature of our dependent variable, which is a count variable, and its distribution, which is skewed toward 0 with an average value close to 1 , we employ a Poisson regression model that can be expressed formally by the link function:

$$
\begin{aligned}
\log (\text { E }[\text { patents }])= & \beta_{1}^{\prime} \text { Breadth }+\beta_{2}^{\prime} \text { Depth }+\beta_{3 B} \text { PubSub } *(\text { Breadth })+\beta_{3 D} \text { PubSub } \\
& *(\text { Depth })+\varepsilon,
\end{aligned}
$$

where the logarithm of the expected number of patent applications is regressed against a set of independent variables of interest, Breadth and Depth, and a set of control variables, $X$.

In particular, in Models (1) and (2) in Table 6 and Models (1) and (2) in Table 7, the terms Breadth and Depth correspond to the aggregate variables Breadth and Depth discussed in the previous section. In Model (3) in Table 6 and Models (3) and (4) in Table 7, we split these variables by geography, as follows.

- The vector Breadth is composed of three variables, Breadth_TN, Breadth_IT and Breadth_EX

- The vector Depth is composed of the three variables, Depth_TN, Depth_IT and Depth_EX

We also employ two additional independent variables in Eq. (1) for the model specifications reported in Table 7: PubSub, which is a proxy of a firm's ability to obtain public funds, and Breadth_Fin, a measure of the breadth of a firm's financial sources. Furthermore, in Models (2) and (4) in Table 7, we include interaction terms between subsidy intensity and Breadth and Depth. In addition, the model contains an error term, $\varepsilon$, with a mean of 0 and finite variance.

The model is estimated using a maximum likelihood method, in which the likelihood function to maximize is given by the following.

$$
\left.\log (L)=\sum y \cdot \log (E[\text { patents } \mid X])-E[\text { patents } \mid X]\right) .
$$


Table 6 Poisson regression models

\begin{tabular}{llll}
\hline Dep. Var.: PatCount & \multicolumn{2}{l}{ Models } & $(3)$ \\
\cline { 2 - 4 } & $(1)$ & $(2)$ & $-0.116(0.048)^{* * *}$ \\
\hline Coll_Inten & $-0.056(0.027)^{* * *}$ & $-0.108(0.048)^{* * *}$ & \\
Breadth & $-0.192(0.373)$ & $-0.672(0.260)^{* * *}$ & \\
Depth_Inten & $0.247(0.333)$ & & \\
Depth & & $0.047(0.010)^{* * *}$ & $0.992(0.350)^{* * * *}$ \\
Breadth_TN & & $0.337(0.353)$ \\
Breadth_IT & & $-11.86(635.7)$ \\
Breadth_EX & & & $-0.009(0.020)$ \\
Depth_TN & & & $0.032(0.015)^{* *}$ \\
Depth_IT & & $0.007(0.004)^{* *}$ & $0.035(0.018)^{* *}$ \\
Depth_EX & $0.006(0.003)^{* * *}$ & $0.168(0.267)$ & $0.005(0.004)$ \\
RDint & $0.134(0.268)$ & $1.891(0.290)^{* * *}$ & $0.582(0.338)^{* *}$ \\
Geomarket & $2.212(0.284)^{* * *}$ & $-1.252(0.360)^{* * *}$ & $1.811(0.311)^{* * *}$ \\
Dummy_hightech & $-1.126(0.321)^{* * *}$ & 84 & $-1.948(0.388)^{* * *}$ \\
Intercept & 84 & 0.247 & 84 \\
N & 0.183 & -117.1 & 0.266 \\
Pseudo R ${ }^{2}$ & -127.1 & 248.2 & -114.2 \\
ll & 268.1 & & 250.4 \\
aic & & &
\end{tabular}

Dependent variable: number of patent applications

ll log likelihood, aic Akaike information criterion

$* * * p<0.01, * * p<0.05, * p<0.10$

Table 6 reports the results of our baseline model, which show that the main determinants of innovation among Trento's R\&D-oriented firms are R\&D intensity and, most importantly, belonging to the high-tech sector. Outward market orientation does not result per se in further contributions to innovation, once we control for the fact that exportoriented firms are most frequently also those that are in the high-tech sector and those that invest in $\mathrm{R} \& \mathrm{D}$ most intensively. Furthermore, our results point to the prevalence of coordination costs associated with managing large networks of collaborations: In all specifications, the sheer number of partnerships, Coll_Inten, is negatively and significantly correlated with innovation.

Model (1), shown by Column (1) in Table 6, applies the specification in Laursen and Salter (2006) to our data. At first, the results would seem to suggest that the measures of breadth and depth of search strategies as defined in Laursen and Salter-variables Breadth and Depth_Inten-would not significantly contribute to innovation. In line with our hypotheses, their signs suggest they operate in opposing directions, with breadth contributing negatively to innovation and depth positively. However, their lack of statistical significance prevents us from drawing further conclusions from the results, bearing in mind that their lack of statistical significance may be due to the small sample size or to the fact that the two variables are highly correlated (pairwise correlation is 0.87 , statistically significant at the $1 \%$ level). 
Table 7 Estimation results

\begin{tabular}{|c|c|c|c|c|}
\hline Dep. Var.: PatCount & (1) & (2) & (3) & (4) \\
\hline Coll_Inten & $-0.077(0.037)^{*}$ & $-0.0583(0.042)$ & $-0.097(0.044)^{* *}$ & $-0.084(0.040)^{* *}$ \\
\hline Breadth_Fin & $0.322(0.083)^{* * *}$ & $0.332(0.091)^{* * *}$ & $0.386(0.149)^{* * *}$ & $0.304(0.126)^{* *}$ \\
\hline PubSub & $-1.312(0.347)^{* * *}$ & $-3.564(1.209)^{* * *}$ & $-3.248(0.737)^{* * *}$ & $-1.473(0.360)^{\text {*** }}$ \\
\hline Breadth & $-0.600(0.292)^{* *}$ & $-0.609(0.322)^{*}$ & & \\
\hline Depth & $0.0356(0.011)^{* * *}$ & $0.031(0.012) * * *$ & & \\
\hline Breadth*PubSub & & $0.227(0.516)$ & & \\
\hline Depth*PubSub & & $0.044(0.025)^{*}$ & & \\
\hline Breadth_TN & & & $1.809(0.489) * * *$ & $0.949(0.413)^{* * *}$ \\
\hline Breadth_IT & & & $0.093(0.461)$ & $-0.204(0.359)$ \\
\hline Breadth_EX & & & $-11.10(1057.5)$ & $-13.83(2929.6)$ \\
\hline Depth_TN & & & $-0.104(0.035) * * *$ & $0.038(0.027)$ \\
\hline Depth_IT & & & $0.019(0.014)$ & $0.024(0.013)^{*}$ \\
\hline Depth_EX & & & $0.077(0.021)^{* * *}$ & $0.0491(0.017)^{* * *}$ \\
\hline Breadth_TN*PubSub & & & & $-2.291(0.809)^{* * *}$ \\
\hline Depth_TN*PubSub & & & & $0.183(0.0421)^{* * *}$ \\
\hline RDint & $-0.001(0.006)$ & $0.001(0.006)$ & $0.012(0.005)^{* *}$ & $0.006(0.005)$ \\
\hline Geomarket & $0.735(0.312)^{* *}$ & $0.786(0.323)^{* *}$ & $0.854(0.343)^{* *}$ & $0.738(0.326)^{* *}$ \\
\hline Dummy_hightech & $1.205(0.338)^{* * *}$ & $1.320(0.355)^{* * *}$ & $1.839(0.421)^{* * *}$ & $1.350(0.354)^{* * *}$ \\
\hline Intercept & $-0.871(0.435)^{* *}$ & $-0.893(0.420)^{* *}$ & $-2.139(0.493) * * *$ & $-1.595(0.436)^{* * *}$ \\
\hline $\mathrm{N}$ & 84 & 84 & 84 & 84 \\
\hline Pseudo $\mathrm{R}^{2}$ & 0.363 & 0.386 & 0.455 & 0.381 \\
\hline 11 & -98.99 & -95.50 & -84.67 & -96.22 \\
\hline aic & 216.0 & 213.0 & 199.3 & 218.4 \\
\hline
\end{tabular}

Poisson regression. Equations including policy measures

$l l$ log likelihood, aic Akaike information criterion

$* * * p<0.01, * * p<0.05, * p<0.10$

A more appropriate specification with which to investigate Hypotheses 1a and $1 \mathrm{~b}$ seems to be the one in Model (2), Column (2) in Table 6, in which we include our preferred measure of depth of search strategies, the variable Depth, which has the advantage of focusing on a different dimension of search strategies, namely the importance and duration of the relationships of a firm with its key individual partners, as opposed to the number of types of partners, which is captured by the variable Breadth. We keep the collaboration intensity, Coll_Inten, as measured by the sheer number of partners, in the specification to control for the fact that a firm having a greater number of partners will necessarily have more depth and breadth than a firm with fewer partners. In Model (2), the breadth of the search strategy in terms of variety in the types of partners (research institutions, other institutions and firms) significantly constrains the patenting ability of a firm. In contrast, the depth of the relationships with individual partners enhances the innovation capacity of the firm. These results suggest that a wider set of partners increases the coordination costs, lending support to Hypothesis 1a, and that drawing intensively from relevant partners contributes to introducing innovation, in line with Hypothesis $1 \mathrm{~b}$. 
The investigation of Hypothesis 2 is undertaken using Model (3) in Table 6, in which we divided the effect of breadth and depth of collaboration in R\&D activities by adding the geographical dimension. As mentioned above, Breadth_TN measures the number of institutional partners of firm $i$ within Trento Province, Breadth_IT measures the number of institutional partners of the same firm in other Italian regions, and Breadth_EX summarizes the same measure with respect to the foreign partners of the firm. Regarding depth, Depth_TN, Depth_IT and Depth_EX measure the importance and duration of the ties of the firm within Trento Province, with other Italian regions and with foreign partners, respectively. The results from this model lend support to our Hypothesis 2a. Indeed, they suggest that there is non-negligible heterogeneity across the effects of breadth and depth strategies at various geographical levels. In particular, a more diversified search strategy at the local level pays off significantly in terms of innovation (Breadth_TN), while diversifying the partnership with Italian partners results in a smaller, still positive, but not significant, effect (Breadth_IT). The breadth of ties with foreign partners (Breadth_EX) is not significant. The monotonic decline of the point estimates associated with greater geographic distance could be explained by increases in the costs of transactions and coordination with more distant and diversified partners.

Hypothesis $2 b$ is investigated through our measures of depth. In this case, the results of the depth variables suggest that the efforts to maintain and deepen a broader network pay off, especially with respect to partners that are geographically more distant. Indeed, while Depth_TN does not have significant results, both Depth_IT and Depth_EX result in positive, significant coefficients of a magnitude similar to those in Model (2) in Table 6. In other words, deep, long-lasting ties with trans-regional and trans-national partners have an especially beneficial effect on innovation. These results support Hypothesis $2 b$ and echo the classical arguments by Granovetter (1985) and Burt (1992) that innovation is more likely to result from non-redundant sources of information (at 'structural holes' or by 'weak' rather than 'strong' ties). Another interpretation of this finding could relate to the type of innovation that we are referring to: new patents necessarily reflect the introduction of radical innovations, while a large part of the innovation process is incremental and is not patented. It is possible that more redundant, local ties contribute to incremental, rather than radical, innovation. Unfortunately, we are unable to explore this possibility further with our data.

In Table 7, we study Hypotheses 3, 4a and 4b, augmenting our models with independent variables related to the sources of a firm's financing, namely the variety of institutions providing fundraising support to the firm and the firm's access to public subsidies. First, we consider the Breadth_Fin variable, which measures the number of different sources the firm has used to find technological partners, develop research projects and identify financing opportunities. In other words, it measures the breadth of the information sources orienting the firm in the development of its $R \& D$ projects. In all the models reported in Table 7, the coefficient of the variable is positive and significant, suggesting that firms relying on a broader set of sources have comparatively fewer budget constraints and are able to more effectively allocate their resources to the most effective technological partners. Put differently, a greater breadth of information sources contributes to a greater ability to innovate. Hence, Hypothesis 3 is not rejected.

The second measure we include is PubSub, which measures the number of times the firm was selected as a beneficiary of R\&D subsidies from 2009 to 2012, which ranges from 0 to 3. In principle, subsidies are expected to complement the R\&D activities of a firm by alleviating the market failures that discourage the innovation process, so we expect a 
positive size of this effect. Models (2) and (4) include interaction terms of the breadth and depth variables with $P u b S u b$.

The findings reported in Table 7 broadly confirm those in Table 6 for the variables that were already included.

Looking at variable PubSub, we find that having benefited from one or more R\&D subsidies from 2009 to 2012 has a significant negative effect on the propensity to innovate (Table 7). Actually, the results suggest that R\&D subsidies, especially if prolonged, become substitutes for the firms' own efforts in R\&D (Aerts and Schmidt 2008).

This result cannot per se be interpreted as evidence that private investments substitute for inefficient efforts at R\&D activity. ${ }^{4}$ Still, the magnitude and negative effect of the PubSub coefficient on the propensity to innovate are quite striking and suggest a careful analysis of the selection of beneficiaries for $R \& D$ subsidies. As a result, Hypothesis $4 b$ is supported by our analysis and Hypothesis 4a is rejected.

Regarding the breadth and depth variables, the magnitudes and signs are the same as in Table 6, while the statistical significance of the estimates is comparatively reduced. As before, the sheer number of partners, Coll_Inten, is statistically significant and negatively correlated with innovation propensity in most specifications; breadth of search strategies with respect to partner type is negative and significant in Models (1) and (2) in Table 7. In contrast, the results for depth are positive and significant, while the findings with respect to the geographical disaggregation of depth and breadth of search strategies are confirmed and further corroborated in Models (3) and (4). Overall, as before, we see that the aggregate measures of depth and breadth fail to account for the fact that firms have differentiated search strategies for partners located within the same region or in foreign countries. Controlling for breadth of fundraising support, Model (3) shows that the more general depth of search strategies within the local area may even be negative, while the depth of ties with geographically more distant partners always has a positive effect on innovation.

The coefficient of the interaction terms with the PubSub variable in Model (2) is not significant for the interaction term with breadth and is positive, but weakly significant, with respect to depth. More insightful results are obtained from Model (4): Regarding breadth, while a more diversified set of local partners contributes positively to innovation, the interaction between the R\&D subsidy and the breadth of search strategies is found to negatively mitigate this effect. On the other hand, deeper relations with local partners negatively affect the innovation propensity of a firm, while the interaction term with PubSub positively mitigates this effect. This may reflect that a share of the collaborations among firms that are associated with public subsidies are ad hoc and do not reflect truly deep relationships among the partners; however, when a subsidy is given to firms with consolidated partnerships, this actually helps to reduce the lock-in effect generated by the local redundancy. These results provide some, although not conclusive, support to Hypotheses $5 \mathrm{a}$ and $5 \mathrm{~b}$.

\footnotetext{
4 A comprehensive evaluation of the effectiveness of the R\&D subsidies on firms' propensities to innovate is beyond the scope of this paper. More generally, a problem of reverse causality running from a firm's innovative propensity to the breadth and depth of its search strategies cannot be excluded here, even if the outcome variable post-dates the regressors in most cases.
} 


\section{Conclusions}

We investigated the role of firms' knowledge search strategies in shaping their innovation performance. Firms use a wide range of external actors and sources to help them achieve and sustain innovation. Our results show that the extension (breadth) and the relevance (depth) of such sources have differentiated effects on firms' abilities to extract and exploit external knowledge and new ideas and, thus, to be innovative.

In particular, our results at the aggregate level supported the hypothesis that a wider set of partners, implying a greater breadth in search strategies, increases the coordination costs and, thus, decreases the innovative ability of the firm. This result partially contradicts previous findings in the literature, which found a positive link between openness and innovation. On the other hand, we find a positive effect of the depth of search strategies. Therefore, rather than simply contradicting the literature, our study points to the existence of a trade-off between increased ability to access external knowledge and increased costs of absorbing this knowledge, and it must be interpreted in light of the prevalence of SMEs in the region under scrutiny.

This interpretation is corroborated by the findings disaggregated by geographical scale. Indeed, we find that the breadth and depth of search strategies at the local, national and global levels have differential effects on innovation. At the local level, where we can expect that the costs of absorbing the knowledge are less, a greater openness to various sources of knowledge - that is, greater breadth - has a very strong positive effect on firms' innovation capacity. The breadth of search strategies at the national level, on which the costs to internalize the knowledge can be expected to be somewhat greater due to differences in the tacit knowledge content, also positively affects innovation, but to a smaller extent, confirming our hypotheses. The finding that the breadth and depth of search strategies with foreign partners contributes negatively, although not significantly so, to innovation further supports the idea that the costs of absorbing this knowledge or, alternatively, the cost of coordination with foreign partners, may outweigh the potential gains from openness.

In contrast, our findings in terms of depth of the search strategies strongly support the idea that the relevance and duration of relationships, rather than their sheer numbers, enable a flow of tacit knowledge and a convergence of routines that allow innovationrelevant synergies. This applies more strongly to more distant - that is, less redundant and potentially more path-breaking — sources of knowledge.

Furthermore, our study sheds light on another dimension of the breadth of search strategies: the information sources consulted prior to and during the elaboration of research projects. The breadth of this set of information sources is found to robustly strengthen the innovation propensity of the firms, suggesting that a better allocation of resources to the process of preparing $\mathrm{R} \& \mathrm{D}$ activities leading to innovation translates into better innovation capacity.

Finally, we find that the most innovative firms are actually not those that rely on public funding, either because of self-selection of less innovative firms among the beneficiaries of public funding, or because the duration of the subsidies has come to substitute for firms' own innovative capacities.

\subsection{Limitations and future perspectives}

The first limitation of the study is related to the measure of innovative outcome that we employ. Indeed, most patents are not commercialized, and they are widely acknowledged 
to be only a partial indicator of the innovation process, since many innovations are not patented at all (Levin et al. 1987; Klevorick et al. 1995). In addition, patents can be considered as an outcome of the appropriability strategy of the firm rather than as an innovation outcome (Teece 1986; Chesbrough 2003a).

Another limitation is related to the geographical scope of the study, which is the result of the decision to focus on a regional context to investigate issues related to spatial aspects-distance of partners-which can shape knowledge transmission differently. Finally, taking into account our results we would also extend the theoretical framework.

Future developments should focus on addressing the first limitation-for example, seeking additional data on innovative sales-to better compare our results with those of Laursen and Salter (2006) and better position the paper in the literature.

Another future development should be to understand the dynamics of the phenomena under investigation, exploiting the longitudinal dimension of the data that could be obtained by replicating the survey. A particularly interesting issue is to tackle the two-way entrepreneurial sides of creating social networks and the use of those networks in terms of the desired innovations, as suggested by Leyden and Link (2015). The dimensions of breadth and depth used in this study could be useful in this regard.

Acknowledgments This research was supported by the Junta de Comunidades de Castilla-La Mancha (research project grant POll-2014-007-A), the Universidad de Castilla-La Mancha (research group grant GI20163573) and the European Union under the European Regional Development Fund (operational programmes 2007ES161PO007 and 2014ES16RFOP010).

Open Access This article is distributed under the terms of the Creative Commons Attribution 4.0 International License (http://creativecommons.org/licenses/by/4.0/), which permits unrestricted use, distribution, and reproduction in any medium, provided you give appropriate credit to the original author(s) and the source, provide a link to the Creative Commons license, and indicate if changes were made.

\section{References}

Acs, Z. J., Audretsch, D. B., \& Lehmann, E. E. (2013). The knowledge spillover theory of entrepreneurship. Small Business Economics, 41(4), 757-774.

Aerts, K., \& Schmidt, T. (2008). Two for the price of one? Additionality effects of R\&D subsidies: Comparison between Flanders and Germany. Research Policy, 37, 806-822.

Ahuja, G. (2000). Collaboration networks, structural holes and innovation: A longitudinal study. Administrative Science Quarterly, 45, 425-455.

Ai, C., \& Norton, E. C. (2003). Interaction terms in logit and probit models. Economics Letters, 80(1), $123-129$.

Arrow, K. J. (1962). Economic welfare and the allocation of resources for invention. In R. Nelson (Ed.), The rate and direction of inventive activity (pp. 609-626). Princeton, NJ: Princeton University Press.

Aw, B. Y., Roberts, M. J., \& Xu, D. Y. (2011). R\&D investment, exporting and productivity dynamics. American Economic Review, 101, 1312-1344.

Basile, R., Capello, R., \& Caragliu, A. (2012). Technological interdependence and regional growth in Europe: Proximity and synergy in knowledge spillovers. Papers in Regional Science, 91(4), 697-722.

Breschi, S., \& Lissoni, F. (2001). Knowledge spillovers and local innovation systems: A critical survey. Industrial and Corporate Change, 10(4), 975-1005.

Burt, R. S. (1992). Structural holes: The social structure of competition. Cambridge, MA: Harvard University Press.

Cerulli, G. (2010). Modelling and measuring the effect of public subsidies on business R\&D: A critical review of the econometric literature. Economic Record, 86, 421-449.

Chesbrough, H. (2003a). Open innovation. Cambridge, MA: Harvard University Press.

Chesbrough, H. (2003b). The era of open innovation. Sloan Management Review, Summer, 35-41. 
Chesbrough, H., \& Vanhaverbeke, W. (2011). Open innovation and public policy in Europe. Research report. Science Business Publishing Ltd. http://www.sciencebusiness.net/Assets/27d0282a-3275-4f028a3c-b93c2815208c.pdf. Accessed July 30, 2015.

Chesbrough, H. W., Vanhaverbeke, W., \& West, J. (2006). Open innovation. Researching a new paradigm. New York: Oxford University Press.

Cohen, W. M., \& Levinthal, D. A. (1990). Absorptive capacity: A new perspective of learning and innovation. Administrative Science Quarterly, 35, 128-152.

Corsino, M., Gabriele, R., \& Giunta, A. (2015). Research and development subsidies: The effectiveness of a regional policy. In P. P. Patrucco (Ed.), The economics of knowledge generation and distribution: The role of interactions in the system dynamics of innovation and growth (pp. 223-251). London: Routledge.

David, P. A., Hall, B. H., \& Toole, A. A. (2000). Is public R\&D a complement or substitute for private R\&D? A review of the econometric evidence. Research Policy, 29(4), 497-529.

Dosi, G. (1988). Sources, procedures and microeconomic effects of innovation. Journal of Economic Literature, 26(3), 1120-1171.

Eurostat. (2015). Regional statistics. http://ec.europa.eu/eurostat/help/new-eurostat-website. Accessed July $30,2015$.

Fazzari, S. M., Hubbard, G. R., \& Petersen, B. C. (1988). Financing constraints and corporate investment. Brookings Papers on Economic Activity, 1, 141-195.

Gabriele, R. (2013). Comportamento d'impresa e politica industriale. Milano: Franco Angeli.

Garcia-Quevedo, J. (2004). Do public subsidies complement business R\&D? A meta-analysis of the econometric evidence. Kyklos, 57, 87-102.

Granovetter, M. (1985). Economic action and social structure: The problem of embeddedness. American Journal of Sociology, 91(3), 481-510.

Hall, B. H. (2002). The financing of research and development. Oxford Review of Economic Policy, 18(1), 35-51.

Hall, B. H., \& Lerner, J. (2010). The financing of R\&D and innovation. In B. H. Hall \& N. Rosenberg (Eds.), Handbook of the economics of innovation (pp. 609-639). Amsterdam: Elsevier-North.

Kaplan, S. N., \& Zingales, L. (1997). Do investment-cash flow sensitivities provide useful measures of financing constraints? The Quarterly Journal of Economics, 112(1), 169-215.

Katila, R. (2002). New product search over time: Past ideas in their prime? Academy of Management Journal, 45, 995-1010.

Katila, R., \& Ahuja, G. (2002). Something old, something new: A longitudinal study of search behavior and new product introduction. Academy of Management Journal, 45(8), 1183-1194.

Klevorick, A. K., Levin, R. C., Nelson, R. R., \& Winter, S. G. (1995). On the sources and significance of interindustry differences in technological opportunities. Research Policy, 24(2), 185-205.

Laursen, K., \& Salter, A. (2006). Open for innovation: The role of openness in explaining innovation performance among UK manufacturing firms. Strategic Management Journal, 27(2), 131-150.

Lee, S., Park, G., Yoon, B., \& Park, J. (2010). Open innovation in SMEs-An intermediated network model. Research Policy, 39(2), 290-300.

Leland, H. E., \& Pyle, D. H. (1977). Informational asymmetries, financial structure, and financial intermediation. Journal of Finance, 32(2), 371-387.

Levin, R., Klevorick, A., Nelson, R. R., \& Winter, S. (1987). Appropriating the returns from industrial research and development. Brookings Papers on Economic Activity, 3, 783-820.

Levinthal, D. A., \& March, J. G. (1993). The myopia of learning. Strategic Management Journal, 14(S2), 95-112.

Leyden, D. P., \& Link, A. N. (2015). Toward a theory of the entrepreneurial process. Small Business Economics, 44, 475-484.

Máñez, J. A., Rochina-Barrachina, M. E., Sanchis-Llopis, J. A., \& Vicente, Ó. (2014). Financial constraints and R\&D and exporting strategies for Spanish manufacturing firms. Industrial and Corporate Change, 23(6), 1563-1594.

Metcalfe, J. S. (1994). Evolutionary economics and technology policy. The Economic Journal, 104(425), 931-944.

Nelson, R. R., \& Winter, S. G. (1982). An evolutionary theory of economic change. Cambridge: Belknap.

Norton, E. C., Wang, H., \& Ai, C. (2004). Computing interaction effects and standard errors in logit and probit models. The Stata Journal, 4(2), 154-167.

Powell, W. W., Koput, K. W., \& Smith-Doerr, L. (1996). Interorganizational collaboration and the locus of innovation: Networks of learning in biotechnology. Administrative Science Quarterly, 41, 116-145.

Rosenkopf, L., \& Nerkar, A. (2001). Beyond local research: Boundary-spanning, exploration, and impact in the optical disk industry. Strategic Management Journal, 22(4), 287-306. 
Schiavone, F. (2008a). The strategic and technological determinants of the structural forms of hi-tech clusters. International Journal of Technoentrepreneurship, 1(4), 296-312.

Schiavone, F. (2008b). Conoscenza, Imprenditorialità, Reti. Padua: CEDAM.

Takalo, T., Tanayama, T., \& Toivanen, O. (2013). Market failures and the additionality effects of public support to private R\&D: Theory and empirical implications. International Journal of Industrial Organization, 31, 634-642.

Teece, D. J. (1986). Profiting from technological innovation: Implications for integration collaboration, licensing and public policy. Research Policy, 15, 285-305.

Villasalero, M. (2013). Signaling, spillover and learning effects of knowledge flows on division performance within related diversified firms. Journal of Knowledge Management, 17(6), 928-942.

Villasalero, M. (2014a). Intra-network knowledge roles and division performance in multi-business firms. Journal of Knowledge Management, 18(6), 1165-1183.

Villasalero, M. (2014b). University knowledge, open innovation and technological capital in Spanish science parks: Research revealing or technology selling? Journal of Intellectual Capital, 15(4), 1469-1930.

Villasalero, M. (2015). Multi-business firms, knowledge flows and intra-network open innovation. Journal of the Knowledge Economy. doi:10.1007/s13132-015-0330-z.

Zeng, S. X., Xie, X. M., \& Tam, C. M. (2010). Relationship between cooperation networks and innovation performance of SMEs. Technovation, 30, 181-194. 